Supplement of Hydrol. Earth Syst. Sci., 24, 2399-2418, 2020

https://doi.org/10.5194/hess-24-2399-2020-supplement

(c) Author(s) 2020. This work is distributed under

the Creative Commons Attribution 4.0 License.

(c) (1)
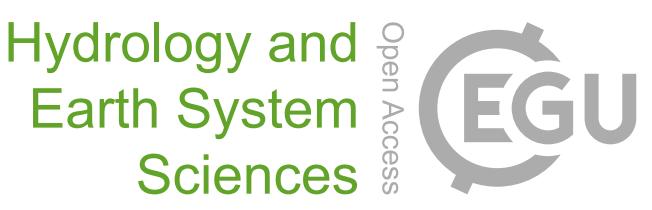

Supplement of

\title{
A novel regional irrigation water productivity model coupling irrigation- and drainage-driven soil hydrology and salinity dynamics and shallow groundwater movement in arid regions in China
}

Jingyuan Xue et al.

Correspondence to: Zailin Huo (huozl@ cau.edu.cn)

The copyright of individual parts of the supplement might differ from the CC BY 4.0 License. 

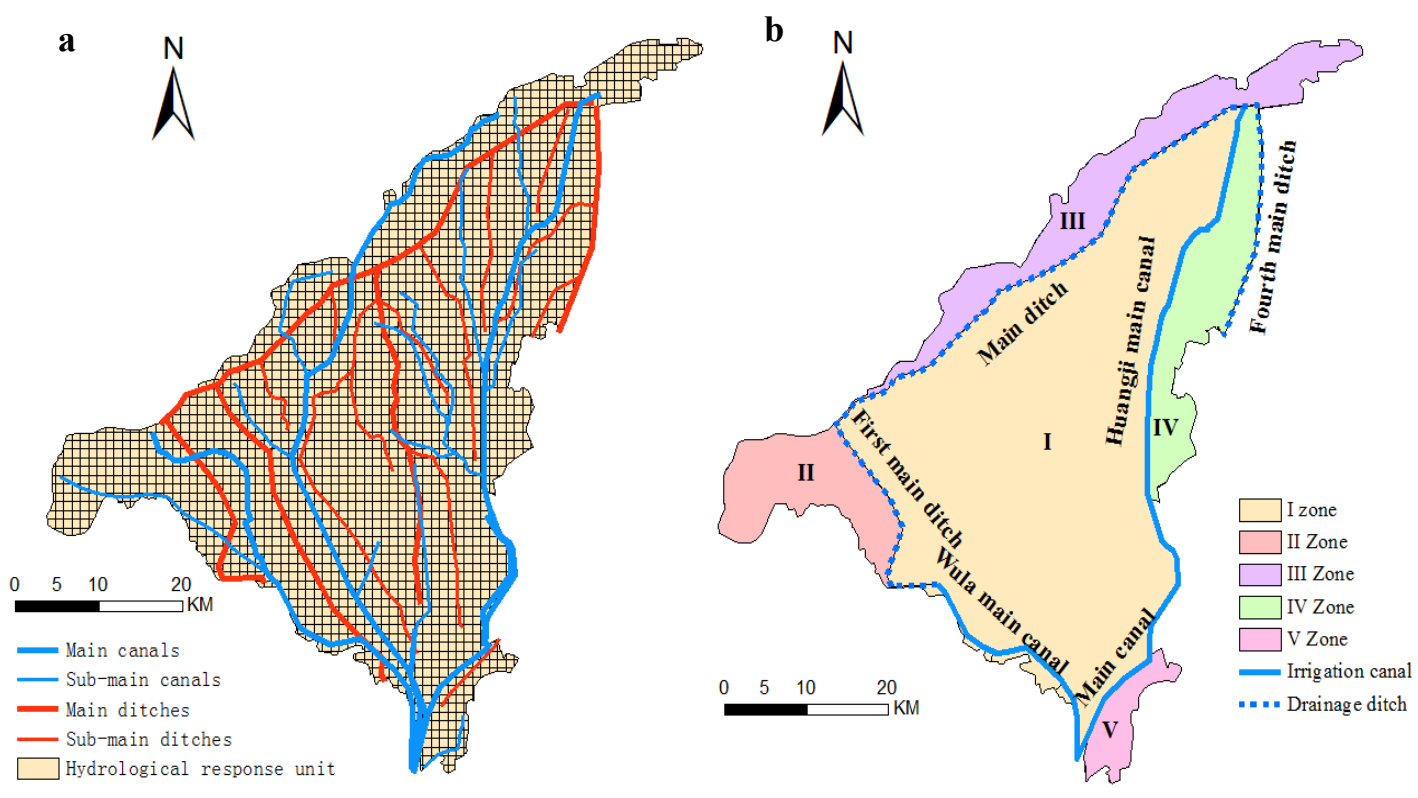

Fig.S1. The representation of (a) regional HRUs division and (b) groundwater boundary condition division.

a

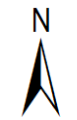

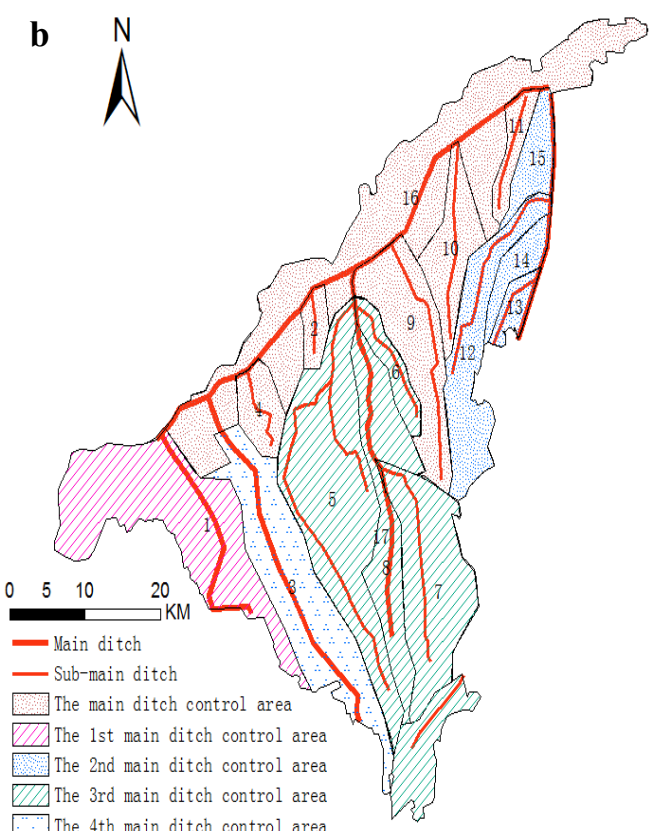

Fig.S2. Spatial distribution and their control zones of main and sub-main (a) canals and (b) drainage ditches. 


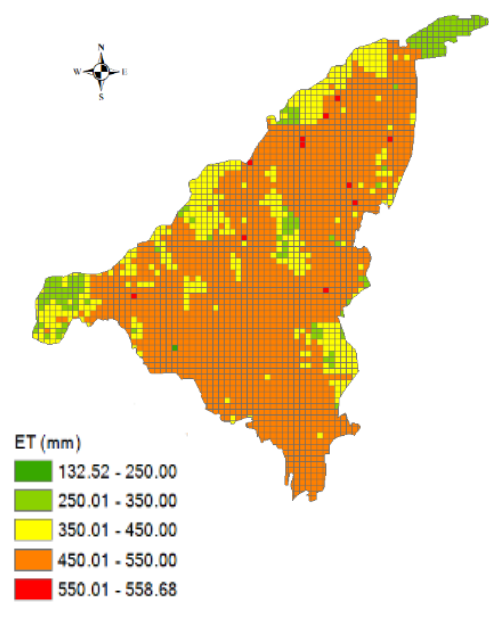

a- Simulated ET (2006)

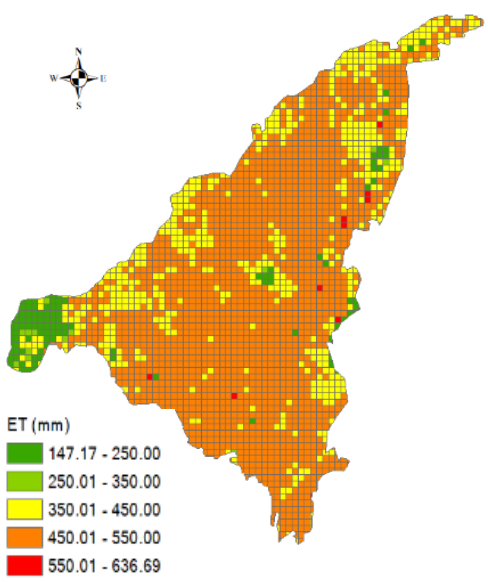

c- Simulated ET (2007)

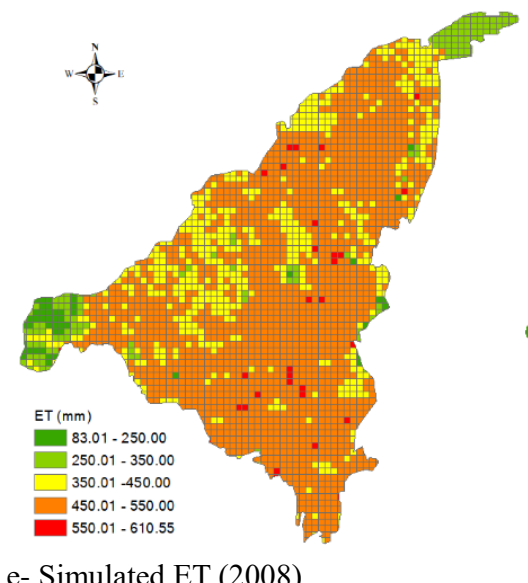

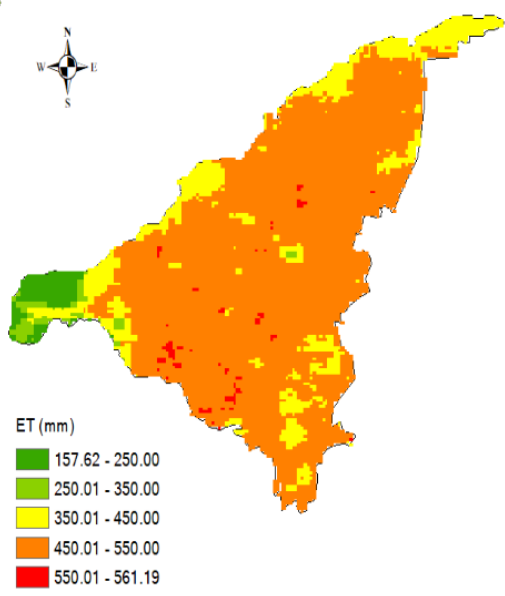

b- Remote sensing ET (2006)

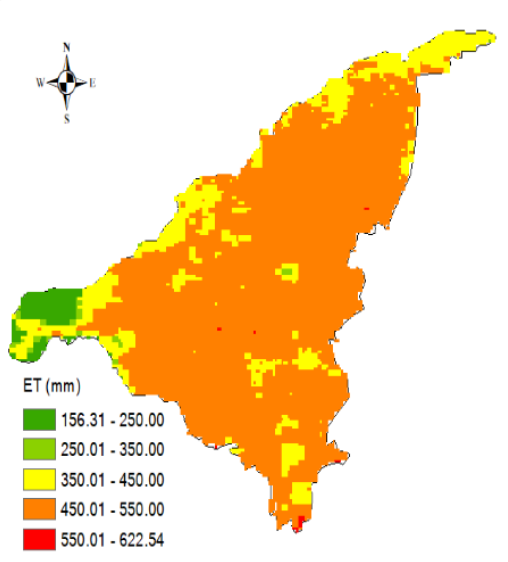

d- Remote sensing ET (2007)

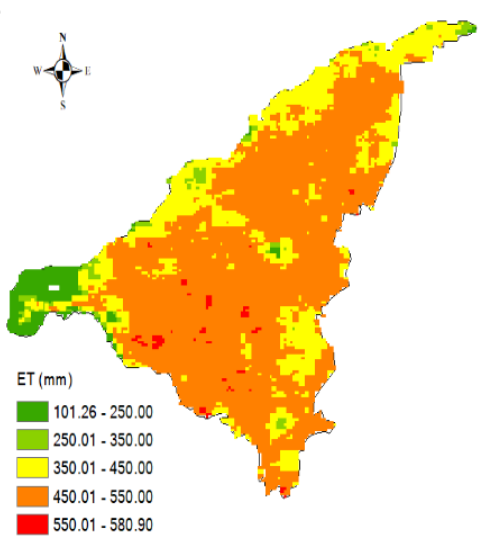

f- Remote sensing ET (2008) 


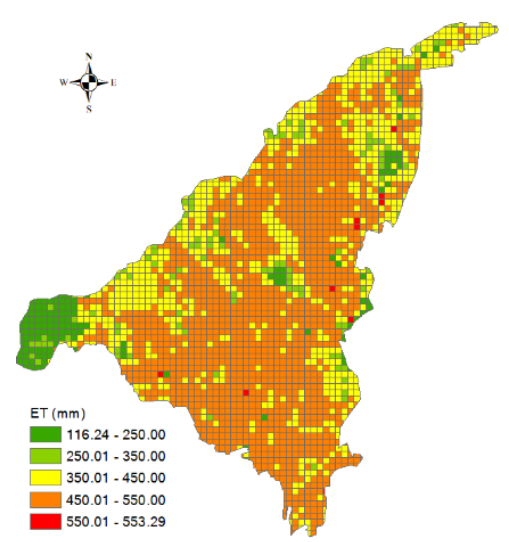

g- Simulated ET (2009)

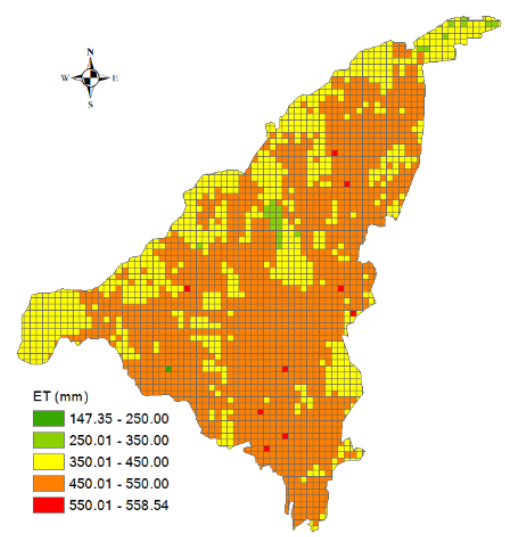

i- Simulated ET (2010)

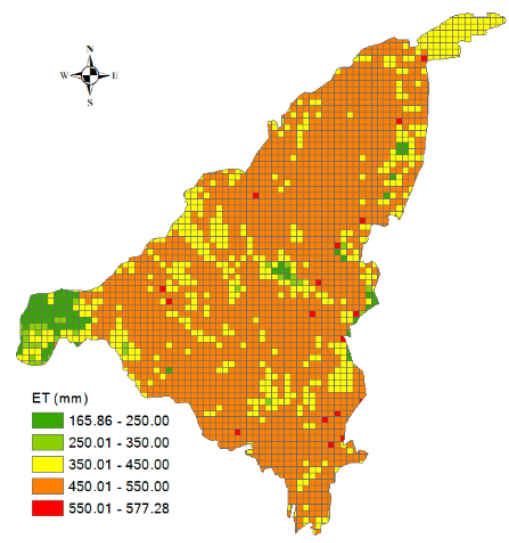

k- Simulated ET (2011)

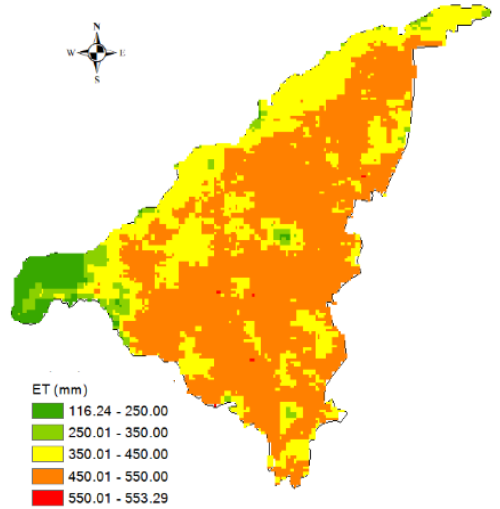

h- Remote sensing ET (2009)

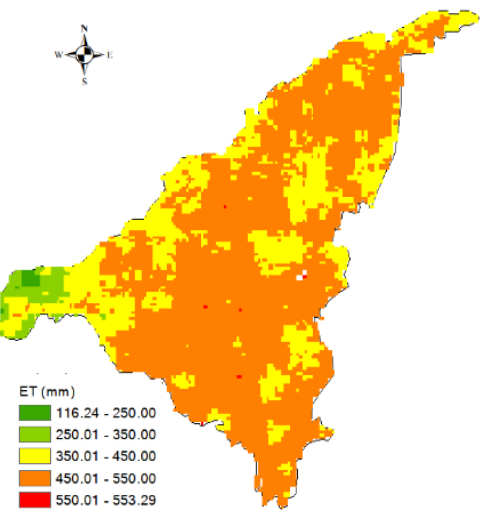

j- Remote sensing ET (2010)

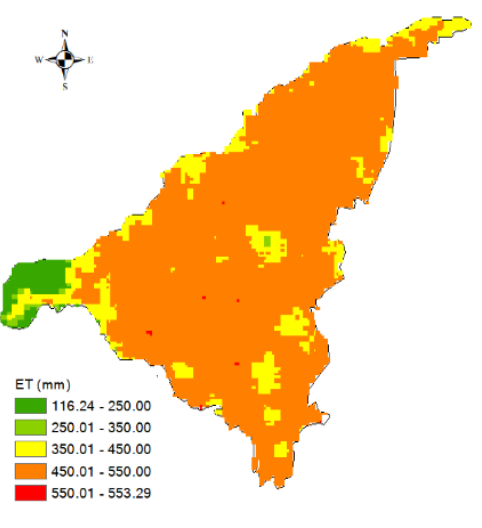

1-Remote sensing ET (2011) 


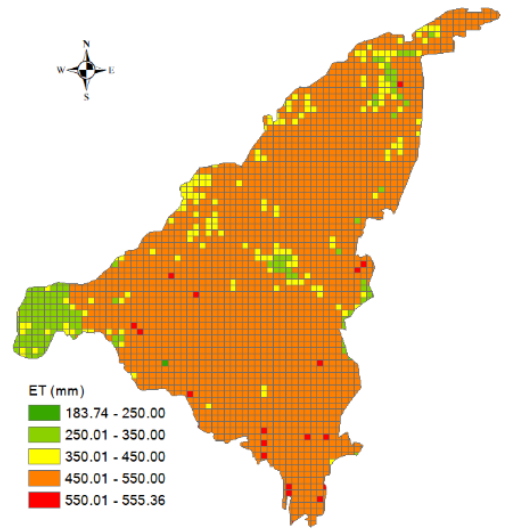

m- Simulated ET (2012)

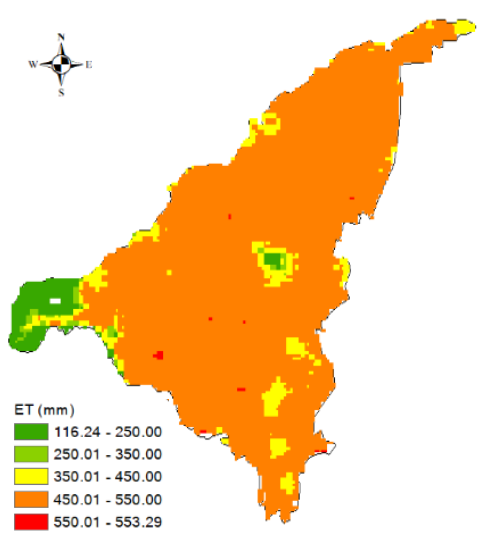

n- Remote sensing ET (2012)

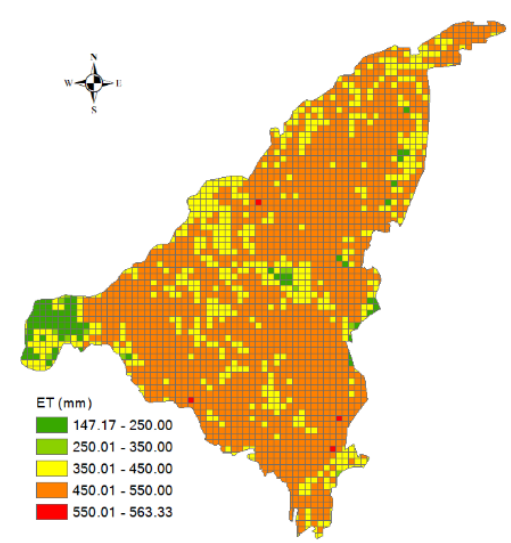

o- Simulated ET (2013)

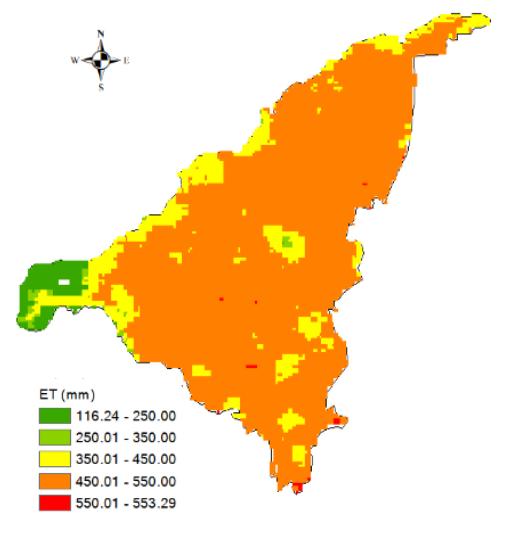

p- Remote sensing ET (2013)

Fig.S3. Comparison of the simulated and remote sensing cumulative ET during the crop growing season in the years of 2006-2013. 